\title{
Erratum to: Fish assemblage patterns in the Elbe estuary: guild composition, spatial and temporal structure, and influence of environmental factors
}

\author{
Dennis Eick • Ralf Thiel
}

Published online: 16 July 2014

(C) Senckenberg Gesellschaft für Naturforschung and Springer-Verlag Berlin Heidelberg 2014

\section{Erratum to: Mar Biodiv}

DOI 10.1007/s12526-014-0225-4

a) In this paper table assignments are erroneous. The correct table assignments are given below:

\begin{tabular}{ll}
\hline Incorrect table assignment: & Correct table assignment: \\
Tables 1 and 2 & Table 1 \\
Table 3 & Table 2 \\
Table 4 & Table 3 \\
Table 5 & Table 4 \\
\hline
\end{tabular}

b) Assignment to Table 5 is missing. Table 5 assignment should be inserted in section "Influence of environmental variables", second paragraph, second sentence that should read as "Here, we evaluated data from official site (FGG Elbe 2013), whereby the highest river run-off in 2009 and 2010 was measured between autumn and spring (Table 5)."

c) Section "Geographical distribution categories", last sentence: "Pale-arctic" is incorrect. Correct is "Pale-Arctic".

Section "Spatial contribution by different ecological guilds and geographical distribution Categories", last sentence:

"Pale-Artic" is incorrect. Correct is "Pale-Arctic".

Section "Contribution of life cycle categories and geographical distribution categories in relation to environmental factors", seventh paragraph, fourth sentence:

"Pale-Artic" is incorrect. Correct is "Pale-Arctic".

d) The author's name "Banarescu" is misspelled in a few cases, correct is "Bănărescu".

e) Table 2 / Station 4 / Geographical distribution categories / Percentage for "Holarctic" is given with "3.6" which is wrong; the correct value is " 7.2 ".

The online version of the original article can be found at http://dx.doi.org/ 10.1007/s12526-014-0225-4. 